\title{
Using a regional numerical weather prediction model for GNSS positioning over Brazil
}

\author{
Daniele Barroca Marra Alves ${ }^{1}$ - Luiz Fernando Sapucci ${ }^{2}$. \\ Haroldo Antonio Marques ${ }^{3}$ Eniuce Menezes de Souza ${ }^{4}$. \\ Tayná Aparecida Ferreira Gouveia ${ }^{1} \cdot$ Jackes Akira Magário $^{1}$
}

Received: 8 October 2014/ Accepted: 14 July 2015/Published online: 6 August 2015

(C) Springer-Verlag Berlin Heidelberg 2015

\begin{abstract}
The global navigation satellite system (GNSS) can provide centimeter positioning accuracy at low costs. However, in order to obtain the desired high accuracy, it is necessary to use high-quality atmospheric models. We focus on the troposphere, which is an important topic of research in Brazil where the tropospheric characteristics are unique, both spatially and temporally. There are dry regions, which lie mainly in the central part of the country. However, the most interesting area for the investigation of tropospheric models is the wet region which is located in the Amazon forest. This region substantially affects the
\end{abstract}

Daniele Barroca Marra Alves

danibarroca@fct.unesp.br

Luiz Fernando Sapucci

luiz.sapucci@cptec.inpe.br

Haroldo Antonio Marques

haroldoh2o@gmail.com

Eniuce Menezes de Souza

emsouza@uem.br

Tayná Aparecida Ferreira Gouveia

tayna.ppgcc@gmail.com

Jackes Akira Magário

jackes_magario@live.com

1 São Paulo State University - UNESP - Brazil, Roberto

Simonsen, 305, Presidente Prudente,

São Paulo State 19060-900, Brazil

2 INPE - Instituto Nacional de Pesquisas Espaciais, Rodovia Presidente Dutra, km 40, Cachoeira Paulista,

São Paulo 12630, Brazil

3 UFPE - Universidade Federal de Pernambuco - Brazil, Rua Academico Hélio Ramos, S/N, Cidade Universitária, Recife, PE 5740-030, Brazil

4 Maringa State University - UEM - Brazil, Colombo Av., 5790, Maringa, Parana State 87020-900, Brazil variability of humidity over other regions of Brazil. It provides a large quantity of water vapor through the humidity convergence zone, especially for the southeast region. The interconnection and large fluxes of water vapor can generate serious deficiencies in tropospheric modeling. The CPTEC/INPE (Center for Weather Forecasting and Climate Studies/Brazilian Institute for Space Research) has been providing since July 2012 a numerical weather prediction (NWP) model for South America, known as Eta. It has yield excellent results in weather prediction but has not been used in GNSS positioning. This NWP model was evaluated in precise point positioning (PPP) and networkbased positioning. Concerning PPP, the best positioning results were obtained for the station SAGA, located in Amazon region. Using the NWP model, the 3D RMS are less than $10 \mathrm{~cm}$ for all $24 \mathrm{~h}$ of data, whereas the values reach approximately $60 \mathrm{~cm}$ for the Hopfield model. For network-based positioning, the best results were obtained mainly when the tropospheric characteristics are critical, in which case an improvement of up to $7.2 \%$ was obtained in 3D RMS using NWP models.

Keywords Numerical weather prediction - Zenithal tropospheric delay $\cdot$ GNSS $\cdot$ Positioning

\section{Introduction}

The global navigation satellite system (GNSS) has revolutionized geodetic positioning by providing positioning with centimeter accuracy in PPP and network-based positioning (Alves and Monico 2011; Marques et al. 2012). In order to obtain this centimeter accuracy over long distances, a major difficulty is finding high-quality ionospheric and tropospheric models. With respect to the 
troposphere, Brazil has a large territory with varying characteristics. Dry regions exist mainly in the northeast and central regions of the country. However, an interesting study area is the northern region located over the Amazon forest. This region is very wet and substantially affects the variability of humidity over other areas of Brazil. It provides a large quantity of water vapor through the humidity convergence zone, especially for the southeastern region. The interconnection and large fluxes of water vapor in the regions can generate serious deficiencies of the tropospheric models.

The empirical models and meteorological information from a standard atmosphere, normally used to reduce the impact of the tropospheric delay, are not able to capture the spatial and temporal variability of the atmosphere. Consequently, in high-accuracy GNSS applications, mainly in real time, this kind of model is not adequate in places like Brazil where the atmospheric conditions are unique. Therefore, there is a need to employ models capable of overcoming the described limitations. An interesting way of obtaining the zenith total delay (ZTD) is a numerical weather prediction (NWP) model, which is based on initial conditions generated from a complete meteorological database in a process known as data assimilation. This methodology has been explored in previous research, and good results have been reported. Rocken et al. (2001) using numerical reanalysis model products obtained a significant reduction in seasonal and latitudinal biases observed in empirical models. Niell (2001) developed an atmospheric mapping function, and Boehm and Schuh ( 2004; Boehm et al. 2006a, b) developed the Vienna Mapping Function (VMF) and the Global Mapping Function (GMF); both developments are based on numerical weather model (NWM). Other research has shown the benefits of integrating NWM and GPS (Schüler et al. 2003; Jensen et al. 2002; Jupp et al. 2003). Strategies based on ray-traced tropospheric slant delay corrections obtained from NWP have been investigated, which demonstrated that small improvements can be obtained with respect to the mapping function approach (Hobiger et al. 2008). Hobiger et al. (2010) showed the improvement obtained in the positioning solutions during extreme weather occurrences, when the standard mapping function approach suffers from the fact that the complex weather situation is not well modeled by the gradient-like asymmetric contribution.

The CPTEC (Center for Weather Forecasting and Climate Studies) at INPE (Brazilian Institute for Space Researches) makes available a regional model of the ZTD for South America (http://satelite.cptec.inpe.br/zenital/). The ZTD values are provided for all of South America in a regular grid twice per day, with predictions for a period of $66 \mathrm{~h}$ (Sapucci et al. 2007). The first versions were tested against the empirical Hopfield model. The results showed a better performance for the NWP model with an improvement of approximately $19 \%$ (Alves et al. 2006; Alves and Monico 2011).

Since June 2012, a new version of the regional NWP model, called Eta, has been available (Chou et al. 2005; Mesinger et al. 2012). Important improvements in the horizontal, vertical, and temporal resolutions were implemented in this version, including a horizontal resolution of $15 \mathrm{~km}, 42$ vertical levels, and a ZTD forecast every $3 \mathrm{~h}$. Here, the main goal is to evaluate the Eta model for precise point positioning (PPP). Using PPP, the model performance will be tested in 5 different regions, with different tropospheric characteristics. Additionally, the model will be tested with regard to network-based positioning using data from the GNSS-SP network. In both methods, data from June 2012 to December 2013 were processed. The theory involved with tropospheric modeling by using NWP, and the Eta model will be described below. In addition, we present the network and software configurations and a description of the experiments and analyses carried out to demonstrate the performance of the model.

\section{Evaluation of tropospheric modeling}

Atmospheric gases cause changes in direction and speed of GPS electromagnetic waves while propagating through different atmospheric layers. These changes cause the actual path of the signal to be longer than the straight geometric distance, resulting in a signal delay, also called tropospheric delay. Mapping functions are used to model these delay variations (Davis et al. 1985; Niell 1996). These mapping functions permit the variations of the tropospheric delay in any direction to be expressed as a function of the ZTD, by considering the concentration of gases in a vertical atmospheric column. In recent years, significant progress has been made in improving mapping functions, especially with the use of NWP products (Boehm and Schuh 2004; Niell 2001).

Due to the behavior of atmospheric gases, the ZTD is divided into two components: the zenith wet delay (ZWD), formed by the influence of water vapor, and the zenith hydrostatic delay (ZHD). The ZHD component depends on the atmospheric air density. Consequently, if the supposition of the hydrostatic balance is true, values with good quality can be estimated from pressure measurements at the surface $P_{0}$, taking into consideration the latitude $\varphi$ and the altitude $h_{0}$ of the location. This relationship can be expressed by following equation (Davis et al. 1985):

$\mathrm{ZHD}=\frac{\left(2.27683157 \times 10^{-3}\right) P_{0}}{\left(1-0.0026 \cos 2 \varphi-0.00028 h_{0}\right)}$

The ZWD values can be obtained by following equation (Davis et al. 1985): 


$$
\mathrm{ZWD}=10^{-6} \int_{h_{0}}^{\infty}\left(k_{2}^{\prime} \frac{e}{T} Z_{w}^{-1}+k_{3} \frac{e}{T^{2}} Z_{w}^{-1}\right) \mathrm{d} h,
$$

where $e$ is the partial pressure of the water vapor and $T$ is temperature, both of which vary as a function of altitude $h$. Additionally, $Z_{\mathrm{w}}^{-1}$ is the inverse of the constant of compressibility of the water vapor, $k_{2}^{\prime}=22.10 \mathrm{~K} \mathrm{hPa}^{-1}$ and $k_{3}=373900 \mathrm{~K}^{2} \mathrm{hPa}^{-1}$, which are constants for the atmospheric refractivity (Bevis et al. 1994). Although the influence of ZHD is smaller than the hydrostatic component, which is approximately $10 \%$ of the ZTD, the temporal and spatial variation is much larger, changing by $20 \%$ in a few hours (Spilker 1996).

\section{Numerical weather prediction models applied in tropospheric modeling}

There is a consensus in the scientific community that the NWP models can contribute significantly to the modeling of the ZTD. The approach involves an atmospheric general circulation model (AGCM), which meticulously accounts for the interactions of the physical phenomena in the terrestrial atmosphere via a complex system that demands high computational capacity (Richardson 1922). This system is constantly fed with and corrected by observations of atmospheric variables, which are provided by various types of sensors. Consequently, the NWP is able to generate ZTD forecasts of better quality than those of the available mathematical models, such as Hopfield and Saastamoinen models.

The principle involved in the NWP model is relatively simple: Knowing the evolution laws of the atmosphere state, the future state can be predicted in the instant $t$, if the initial state is known at the instant $t_{0}$. The ZWD forecast can be obtained by applying the profiles of temperature and humidity predicted by the NWP model using numeric integration of (2). In a similar way, the ZHD forecast is obtained by applying the values of the atmospheric pressure at the surface predicted by model and the coordinates of the respective point in (1). Adding both components yields the forecasts of the ZTD for each individual point belonging to model domain. Interpolation methods can be used to obtain ZTD values for any other internal point of the model domain, which makes it possible to analyze the seasonal ZTD variability over South America.

\section{Eta model with a $15 \mathrm{~km}$ horizontal resolution}

The Eta model is a descendent of the earlier HIBU (Hydrometeorological Institute and Belgrade University) model (Mesinger and Janjic 1974). The code has been upgraded to the Arakawa-style horizontal advection scheme of Janjic (1984), then rewritten to use the Eta vertical coordinate (Mesinger et al. 1988), and subsequently, at NCEP, supplied with an advanced physics package (Janjic 1990; Mesinger and Lobocki 1991).

One of the most significant differences between Eta and other NWP models is the vertical coordinate, which was defined by Mesinger (1984) and which provides the name of this model. Using this vertical coordinate defines quasihorizontal coordinate surfaces and thus prevents pressuregradient force errors due to steep topography that can occur with terrain-following coordinates (Mesinger 1984). This feature is particularly useful for regions with steep orography such as South America because of the presence of the Andes Cordillera (Chou et al. 2005). The Eta coordinate at an atmospheric point with pressure $P$ is defined by the following expression:

$\eta=\left(\frac{p-p_{T}}{p_{S}-p_{T}}\right)\left[\frac{p_{\mathrm{REF}}(z)-p_{T}}{p_{\mathrm{REF}}(0)-p_{T}}\right]$

where the indices $S$ and $T$ refer to the terrestrial surface and the top of the model atmosphere, respectively. The index REF refers to a prescribed reference atmosphere, and $z$ is the surface height. The model prognostic variables are as follows: surface pressure, horizontal wind components, temperature, specific humidity, turbulent kinetic energy, and cloud hydrometeors.

The Eta model became officially operational at CPTEC in 1996. During the last few years, CPTEC has significantly enlarged the computational capacity and consequently the spatial resolution of its models. The Eta model began with a horizontal resolution of $80 \mathrm{~km}$; currently, it has a resolution of $15 \mathrm{~km}$. The function of the regional model is complementary to the forecast generated by the global model by providing a detailed forecast of phenomena associated with fronts, orography, marine breezes, and severe storms (Chou et al. 2005). Such systems, in a fine temporal scale, exhibit nonlinear behavior; consequently, the period of reasonable forecast accuracy is smaller and the forecast periods are frequently shorter. The forecasts operationally extend to $72 \mathrm{~h}$. Eta covers a large part of South America and adjacent oceans (longitudes from $25^{\circ} \mathrm{W}$ to $90^{\circ} \mathrm{W}$ and latitudes from $12^{\circ} \mathrm{N}$ to $45^{\circ} \mathrm{S}$ ), and its forecast are available twice per day. It will be evaluated using only data from the Brazilian territory.

\section{Hopfield model}

The Hopfield (1969) model assumes that atmospheric refractivity $N$ is a function of temperature $T_{0}$, humidity $e_{0}$, and pressure $P_{0}$ measurement at the surface and of the height of the atmospheric layers involved in the hydrostatic and wet components of the ZTD, which are labeled here by $H_{\mathrm{H}}$ and $H_{\mathrm{W}}$, respectively. This model is based on equations 
presented by Smith and Weintraub (1953), Hopfield (1969), and contributions by Seeber (1993), generating the following algorithm:

$$
\begin{aligned}
& \mathrm{ZHD}=1552 \times 10^{-7} \frac{P_{0}}{T_{0}} H_{\mathrm{H}} \\
& \mathrm{ZWD}=1552 \times 10^{-7} \frac{4810 e_{0}}{T_{0}^{2}} H_{\mathrm{W}} \\
& H_{\mathrm{H}}=40.136+14,872\left(T_{0}-27,316\right) \\
& H_{\mathrm{W}}=11.000 \\
& m h(E)=\left(\sin \left(E^{2}+6.25\right)^{1 / 2}\right)^{-1} \\
& m w(E)=\left(\sin \left(E^{2}+2.25\right)^{1 / 2}\right)^{-1} \\
& \mathrm{ZTD}=\mathrm{ZHD} m h(E)+\mathrm{ZWD} m w(E)
\end{aligned}
$$

where $m h$ and $m w$ are mapping functions for hydrostatic and wet ZTD components, respectively. The term $E$ is the elevation angle of the GPS satellite.

\section{GNSS network of Brazil}

The continuous GNSS network RBMC (Rede Brasileira de Monitoramento Contínuo-Continuous Monitoring Brazilian Network, http://www.ibge.gov.br/english/geo ciencias/geodesia/rbmc/rbmc.shtm) covers all of Brazil. It currently consists of about 110 reference stations that are not uniformly distributed, featuring a lower density of stations across certain regions such as the Amazon forest. Figure 1 (green symbols) shows the distribution of the RBMC stations.

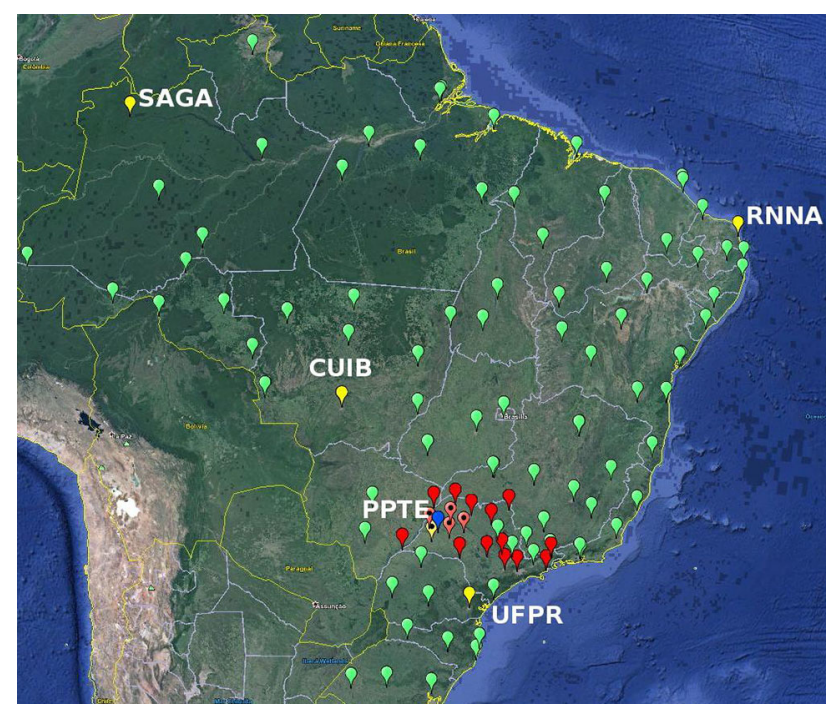

Fig. 1 RBMC stations SAGA, RNNA, CUIB, PPTE, and UFPR (yellow) used in the PPP tests and GNSS/SP stations (red) applied in network-based positioning
Unfortunately, the RBMC cannot support high-precision network-based positioning due to the sparse station spacing. This limitation can be lessened for users in São Paulo State who can access data from the GNSS-SP network (GPS Active Network of São Paulo State). The main objectives of this network are to increase the number of active GNSS stations and to support research on the atmosphere, networkbased positioning, and related fields. The data are available in real time through the Internet using the NTRIP (Networked Transport of RTCM via Internet Protocol) or for post-processed applications (http://www.fct.unesp.br/\#!/ pesquisa/grupos-de-estudo-e-pesquisa/gege//home/).

The GNSS-SP network is maintained by UNESP (Sao Paulo State University), and it is composed of approximately 20 receivers. Currently, the distance between the stations ranges from 100 to $200 \mathrm{~km}$. All receivers stream data to a central facility at UNESP Presidente Prudente, SP, where the data are stored and distributed to the users. Figure 1 (red symbols) shows the distribution of the stations in the São Paulo State region and its borders.

\section{Methodology}

The focus is on PPP results using the NWP and Hopfield models for stations from the RBMC where the ground-truth coordinates are available for comparison. Additionally, the network-based positioning will be tested. In both methods, we obtained the daily solution from static mode using NWP and Hopfield models. The results were evaluated in terms of discrepancies, standard deviations (SD), and root mean squares (RMS).

\section{$P P P$}

Experiments were carried out in the static PPP mode by using the in-house software called RT_PPP, which is capable of processing data in real time and also in postprocessed mode (Marques et al. 2012). The RT_PPP allows the processing of dual-frequency GPS data by employing a Kalman filter and the DIA method (detection, identification, and adaptation) for quality control (Teunissen 1998). The first-order ionospheric effects were corrected by applying the ionospheric-free linear combination. When $\mathrm{C} 1$ observable is available, we apply the DCB (P1-C1) to align the observations. When $\mathrm{L} 2 \mathrm{C}(\mathrm{C} 2)$ is available, it is used instead of P2, applying DCB ( $\mathrm{P} 2-\mathrm{C} 2)$. The troposphere delay can be corrected from the Hopfield model or from CPTEC numerical weather forecast model (ZTD/CPTEC) and also by applying troposphere wet component estimation. The software also applies final satellites orbits and clocks corrections from IGS, absolute PCV (phase center variation) for receivers and satellites, phase windup, relativity effects, OTL (ocean tide loading), and EBT (Earth 
body tide) among others. The ambiguities are estimated as float solutions, and when a cycle slip is detected, the ambiguity parameter is reinitialized.

GPS data from five Brazilian stations (Fig. 1-yellow symbols) during the period of June 2012 to December 2013 were processed in the static PPP mode with daily coordinate estimates. These stations were chosen to evaluate the Eta model in various regions of Brazil, considering different climatic characteristics and data availability.

All PPP corrections were applied, and the troposphere was modeled in the PPP processing via two different strategies, i.e., application of the Hopfield model and the ZTD from NWP/CPTEC. The Hopfield model has an implicit mapping function, and, in case of NWP/CPTEC, the global mapping function (GMF) was applied (Boehm et al. 2006a, b). Furthermore, pressure and temperature values for Hopfield model were obtained from GPT (global pressure and temperature) function (Boehm et al. 2007). Data were processed by taking into account an elevation cutoff of $10^{\circ}$ and adopted observation precisions as $0.8,1$, 0.008 , and $0.001 \mathrm{~m}$ for $\mathrm{C} 1, \mathrm{P} 2$, phase $\mathrm{L} 1$, and phase $\mathrm{L} 2$, respectively. The estimated coordinates were compared with ground-truth coordinates to analyze the accuracy reached when considering the two troposphere correction strategies. The results and analysis can be seen in the next sections.

\section{Zenithal wet delay}

The ZWD was estimated in the RT_PPP as a random walk stochastic process in the Kalman filter with a priori spectral density equal to $5 \mathrm{~mm}$ per hour. In this case, the GMF is applied and the hydrostatic component comes from Hopfield model. Considering the ZWD estimated in each epoch during the daily solution, a ZWD daily average was computed; Fig. 2 shows the time series for stations SAGA, RNNA, CUIB, PPTE, and UFPR. Additionally, we also present in the same figure the daily average of ZWD obtained by the NWP and Hopfield models. It is possible to note that ZWD obtained by the NWP model is similar to the estimated solution.

\section{Network-based positioning}

At São Paulo State University, an in-house software system is under development for generating network-based corrections using the VRS concept. In the proposed method, atmospheric models are used to generate network corrections. Details about the software methodology can be found in Alves and Monico (2011). This software was used to generate the VRS data.

Data from the GNSS/SP network (Fig. 1-red symbols) were used to perform the network-based positioning. VRS

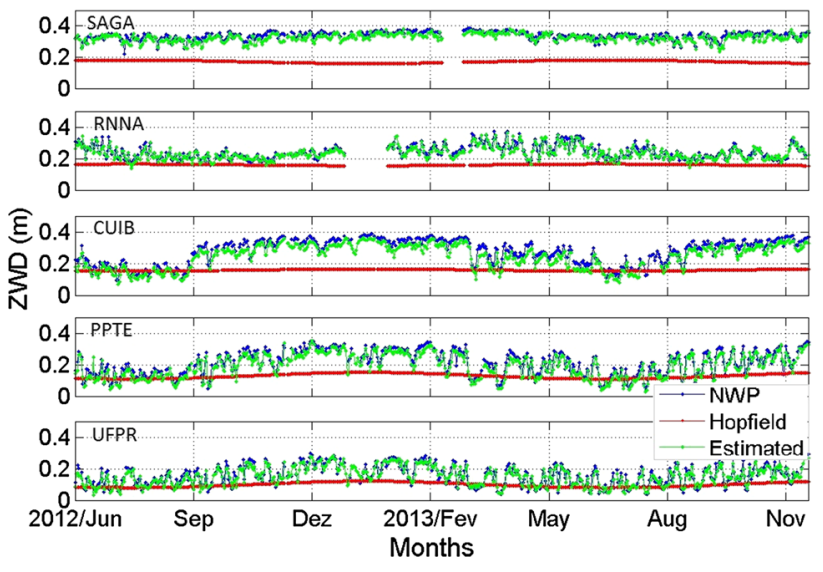

Fig. 2 Daily ZWD obtained by NWP and Hopfield models and estimated during PPP processing for stations SAGA, RNNA, CUIB, PPTE, and UFPR

data were generated using the subnetwork west of São Paulo State (symbols with an inner circle). Station PPTE (yellow symbol with inner circle) was used as the base station because it is closest to the VRS position (blue symbol). The VRS was generated approximately $40 \mathrm{~km}$ from PPTE station.

To accomplish the experiments, we generated VRS data for the same period of the PPP solutions, i.e., from June 2012 to December 2013. Additionally, VRS data were generated using the Hopfield and NWP/CPTEC models. The next step was to evaluate the VRS data quality. Here, we used the RT_PPP software and PPP static mode.

\section{Results and analysis}

This section presents the results obtained by PPP and network-based positioning. We also illustrate the daily ZWD estimated during PPP processing and ZWD obtained using Hopfield and NWP models.

\section{Zenithal wet delay}

Analyzing Fig. 2 is possible to verify that the values obtained by estimated ZWD and NWP models are quite similar, but that the Hopfield model presents fairly constant results and is, therefore, not able to capture the temporal variability of ZWD values.

\section{Ppp}

Figure 3 presents the horizontal and vertical RMS values obtained for station SAGA using the PPP static mode and the Hopfield and NWP Eta models. Figure 4 presents 3D RMS obtained for stations SAGA, RNNA, CUIB, PPTE, 

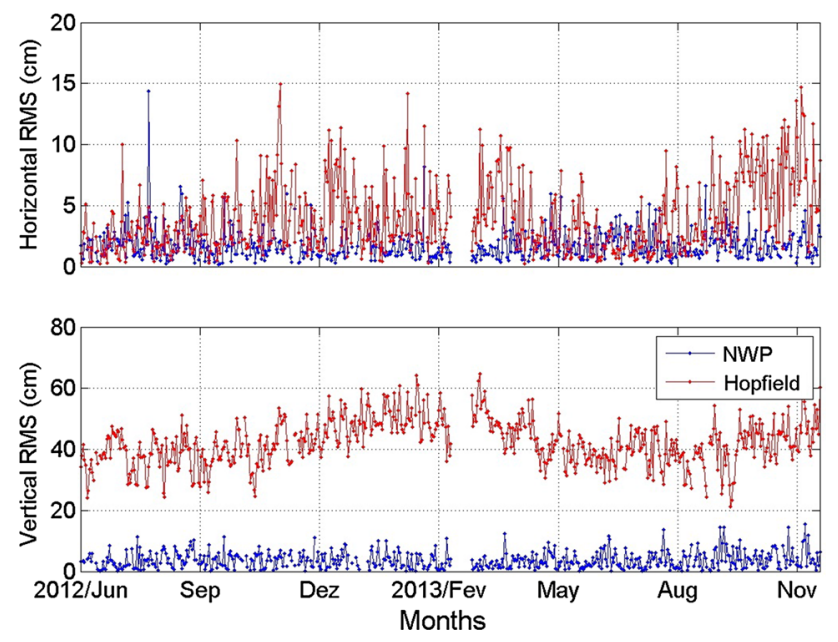

Fig. 3 Horizontal and vertical RMS values obtained by PPP static mode for station SAGA using the NWP and Hopfield tropospheric models

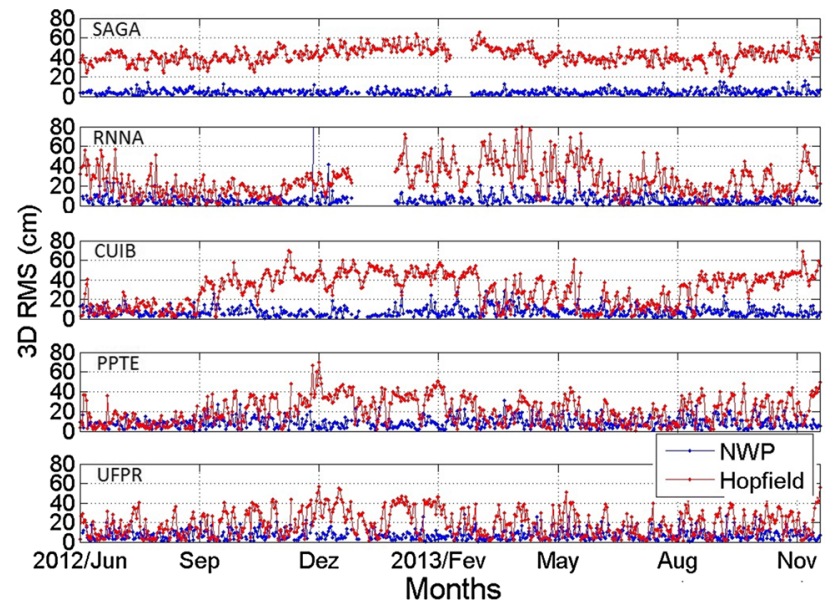

Fig. 4 PPP static mode results obtained by stations SAGA, RNNA, CUIB, PPTE, and UFPR and NWP and Hopfield tropospheric models

and UFPR. For SAGA and RNNA stations, some gaps can be seen in these figures due to lack of RINEX observation files.

With regard to the SAGA station, Figs. 3 and 4 show that the RMS values for the Hopfield model are larger than those for the NWP model. The most important result from these stations is the high accuracy of the ZTD modeling using NWP, which captures the seasonal oscillation during the annual cycle. The Hopfield model exhibits poor accuracy during the summer, whereas the results obtained by the Eta model feature lower RMS values and are seasonally independent. Using the NWP model, the values are less than $10 \mathrm{~cm}$ for all $24 \mathrm{~h}$ of data, whereas the values reach approximately $60 \mathrm{~cm}$ for the Hopfield model.

By evaluating the time series for station RNNA in Fig. 4, it is possible to note large RMS values associated with the Hopfield model. The errors reach 80 and $20 \mathrm{~cm}$ for the Hopfield and NWP models, respectively. This station is located near the sea, where humidity is also relevant.

The station CUIB is located in a dry central region of Brazil. The figure shows that, in general, the NWP model presented the best results. Better results were obtained for the summer season (December to March), which is the wettest period of year, and the rain events are more frequent.

Although station PPTE is located far from the coast, it receives humidity from the Amazon forest when the South Atlantic convergence zone (SACZ) is active, which is very common during the period from November to March. The figure shows that the behavior of the NWP model is better, especially during the SACZ occurrence period. Using this model, the 3D RMS values are less than $15 \mathrm{~cm}$, but when Hopfield model is used, the 3D RMS values reach $70 \mathrm{~cm}$.

Station UFPR is located in the south of Brazil. The analysis of the 3D RMS values shows that the Hopfield results are larger than those of NWP. While the Hopfield RMS values reach almost $60 \mathrm{~cm}$, the NWP results are approximately $10 \mathrm{~cm}$. Similar to the other stations, the horizontal discrepancies of this station are minor between the two models, and the largest difference exists in the altitude component.

In Table 1, we evaluate the median absolute error (MAE) and the median absolute deviation (MAD) statistics from the time series presented in Figs. 3 and 4. These statistics are robust measures for non-normal distributed data and insensitive to outliers. We also calculate the error reduction factor (RF) when NWP is used instead of the Hopfield tropospheric model (HOP/NWP).

In the evaluation of time series, the mean level is not an adequate representation when trend or cycle effects are present. This can be seen in Table 1 from MAD, which represents not only the bias reduction but also the absolute deviation around the median of the daily estimated coordinates. For the Hopfield model, the greatest problem is that the daily $3 \mathrm{D}$ value can be very good one day, with few millimeters of discrepancy, but as large as $80 \mathrm{~cm}$ on another days. Furthermore, as expected, the reduction factor shows that the improvements were more relevant for the vertical coordinates (3D relative to horizontal results), reaching a reduction factor of about 9 in the MAE for station SAGA. The 3D MAD errors were in general 3 times larger for the HOP tropospheric model than for NWP.

\section{Network-based positioning}

Figure 5 shows the 3D RMS values obtained with the VRS data files generated using the NWP and Hopfield tropospheric models. By evaluating the time series presented in the figure, it is clear that the results obtained by both 
Table 1 Median absolute error (MAE) and the median absolute deviation (MAD) for the horizontal and 3D time series in PPP static positioning using the NWP and Hopfield tropospheric models

\begin{tabular}{|c|c|c|c|c|c|c|c|c|c|c|c|c|}
\hline \multirow[t]{3}{*}{ Stations } & \multicolumn{6}{|c|}{ Horizontal $(\mathrm{cm})$} & \multicolumn{6}{|c|}{ 3D (cm) } \\
\hline & \multicolumn{3}{|l|}{ MAE } & \multicolumn{3}{|c|}{ MAD } & \multicolumn{3}{|l|}{ MAE } & \multicolumn{3}{|l|}{ MAD } \\
\hline & HOP & NWP & $\mathrm{RF}$ & HOP & NWP & $\mathrm{RF}$ & HOP & NWP & $\mathrm{RF}$ & HOP & NWP & RF \\
\hline CUIB & 1.82 & 2.13 & 0.85 & 0.52 & 0.5 & 1.04 & 31.54 & 7.8 & 4.04 & 12.66 & 3.52 & 3.60 \\
\hline PPTE & 0.95 & 0.94 & 1.01 & 0.46 & 0.42 & 1.10 & 18.42 & 8.82 & 2.09 & 10.23 & 3.92 & 2.61 \\
\hline RNNA & 1.55 & 1.51 & 1.03 & 0.68 & 0.6 & 1.13 & 21.78 & 5.3 & 4.11 & 10.06 & 2.74 & 3.67 \\
\hline SAGA & 3.16 & 1.44 & 2.19 & 1.84 & 0.6 & 3.07 & 38.32 & 4.35 & 8.81 & 5.12 & 1.99 & 2.57 \\
\hline UFPR & 1.02 & 1.07 & 0.95 & 0.41 & 0.41 & 1.00 & 16.33 & 5.84 & 2.80 & 10.48 & 3.38 & 3.10 \\
\hline
\end{tabular}

acceptable. In network-based positioning, the errors are computed in a relative mode, which attenuate the results. Additionally, the GNSS-SP network is located in a dry region.

There are certain periods, mainly when the troposphere characteristics are critical, that the NWP model has a better performance. This occurs, for example, in June where the humidity is very low in this region. Figure 6 shows the horizontal and vertical RMS values for this period. The figures show that the NWP model yields the best results. The average 3D RMS values are 2.98 and $3.22 \mathrm{~cm}$ for the NWP and Hopfield models, respectively, an improvement of $7.2 \%$.

In Table 2, we can evaluate the MAE, MAD, and the error reduction factor when NWP is used instead of the Hopfield tropospheric model from the time series presented in Figs. 5 and 6. The table shows that the improvements were much smaller than in PPP. When all periods are considered, the results obtained by both models are quite similar. In a critical month, like July, the results of the NWP model are better.

\section{Conclusions}

We presented a new NWP tropospheric model available in Brazil, known as the Eta model. Although this model has yielded satisfactory results with improvement of the spatial resolutions over South America in comparison with empirical models (Alves et al. 2006; Alves and Monico 2011), it still had not been evaluated with regard to GNSS positioning. In order to do this verification, this new NWP tropospheric model was applied in PPP and network-based tropospheric models are quite similar, yielding a $2.8-\mathrm{cm}$ RMS on average. Considering the network-based positioning methodology and the network used, the results are
Table 2 Median absolute error (MAE) and the median absolute deviation (MAD) for horizontal and 3D time series obtained by PPP static mode for the VRS data files generated using the NWP and Hopfield tropospheric models

\begin{tabular}{|c|c|c|c|c|c|c|c|c|c|c|c|c|}
\hline \multirow[t]{3}{*}{ Period } & \multicolumn{6}{|c|}{ Horizontal $(\mathrm{cm})$} & \multicolumn{6}{|c|}{$3 \mathrm{D}(\mathrm{cm})$} \\
\hline & \multicolumn{3}{|l|}{ MAE } & \multicolumn{3}{|l|}{ MAD } & \multicolumn{3}{|l|}{ MAE } & \multicolumn{3}{|c|}{ MAD } \\
\hline & $\mathrm{HOP}$ & NWP & $\mathrm{RF}$ & $\mathrm{HOP}$ & NWP & $\mathrm{RF}$ & $\mathrm{HOP}$ & NWP & $\mathrm{RF}$ & HOP & NWP & $\mathrm{RF}$ \\
\hline All periods & 1.89 & 1.83 & 1.03 & 0.39 & 0.39 & 1.00 & 2.89 & 2.8 & 1.03 & 0.54 & 0.5 & 1.08 \\
\hline July 2012 & 2.19 & 2.06 & 1.06 & 0.29 & 0.26 & 1.12 & 3.14 & 2.89 & 1.09 & 0.26 & 0.27 & 0.96 \\
\hline July 2013 & 2.03 & 1.74 & 1.17 & 0.25 & 0.31 & 0.81 & 3.45 & 3.21 & 1.07 & 0.37 & 0.38 & 0.97 \\
\hline
\end{tabular}


positioning and the obtained results are presented and discussed here.

First, PPP was carried out at five different Brazilian stations with different tropospheric characteristics. The best results were obtained by the NWP model for all stations. In high-humidity regions, which include the SAGA station, the improvements were more significant. For this station, improvements of about a factor of 3 were obtained for both horizontal and 3D MAD. In an additional analysis, we evaluated the network-based positioning using data from the GNSS/SP network. In these tests, the results presented by both models were quite similar when considering the entire period. The NWP exhibited the best results only in months that featured critical tropospheric characteristics, such as July. Ideally, we should be able to use data from a network located very the Amazon forest or the coast, where the humidity is very high. However, in Brazil, this is not possible because of sparse station spacing. This might be possible in the future.

Considering these results, we can conclude that the NWP Eta model yields high-quality tropospheric predictions. Consequently, it is possible to use this model instead of empirical models to obtain a noticeable improvement in GNSS positioning.

Acknowledgments The authors would like to thank FAPESP and $\mathrm{CNPq}$ for the financial support provided to this research (FAPESP research project-process number 2012/19906-7; CNPQ research scholarship_-process number 303079/2011-8).

\section{References}

Alves DBM, Monico JFG (2011) GPS/VRS positioning using atmospheric modeling. GPS Solut 15(3):253-261

Alves DBM, Monico JFG, Dalbelo LFA, Sapucci LF, Camargo PO (2006) VRS concept using NWP and Mod_Ion_FK: preliminary results in Brazil. Proc. International FIG Congress. Munich, Germany, 1-14

Bevis M, Businger S, Chriswell S, Herring TA, Anthes RA, Rocken C et al (1994) GPS meteorology: mapping zenith wet delays onto precipitable water. J Appl Meteorol 33:379-386

Boehm J, Schuh H (2004) Vienna mapping functions in VLBI analyses. Geophys Res Lett. doi:10.1029/2003GL018984

Boehm J, Niell A, Tregoning P, Schuh H (2006a) Global mapping function (GMF): a new empirical mapping function based on numerical weather model data. Geophys Res Lett 33(7):1-4. doi: $10.1029 / 2005$ GL025546

Boehm J, Werl B, Schuh H (2006b) Troposphere mapping functions for GPS and very long baseline interferometry from European centre for medium-range weather forecasts operational analysis data. J Geophys Res 111(B2):1-9. doi:10.1029/2005JB003629

Boehm J, Heinkelmann R, Schuh H (2007) Short note: a global model of pressure and temperature for geodetic applications. J Geod 81(10):679-683. doi:10.1007/s00190-007-0135-3

Chou SC, Bustamante JF, Gomes JL (2005) Evaluation of seasonal precipitation forecasts over South America using Eta model. Nonlin Proc Geophys 12:537-555
Davis JL, Herring TA, Shapiro I, Rogers AE, Elgened G (1985) Geodesy by interferometry: effects of atmospheric modeling errors on estimates of base line length. Radio Sci 20:1593-1607

Hobiger T, Ichikawa R, Koyama Y, Kondo T (2008) Fast and accurate ray-tracing algorithms for real-time space geodetic applications using numerical weather models. J Geophys Res 113(D20302):1-14. doi:10.1029/2008JD010503

Hobigera T, Shimadab S, Shimizub S, Ichikawaa R, Koyamaa Y, Kondoa T (2010) Improving GPS positioning estimates during extreme weather situations by the help of fine-mesh numerical weather models. J Atmos Solar Terr Phys 72:262-270

Hopfield HS (1969) Two-quartic tropospheric refractivity profile for correcting satellite data. J Geophys Res 74(18):4487-4499

Janjic ZI (1984) Nonlinear advection schemes and energy cascade on semi-staggered grids. Mon Weather Rev 112(6):1234-1245

Janjic ZI (1990) The step-mountain coordinate: physical package. Mon Weather Rev 118(7):1429-1443

Jensen ABO, Tscherning CC, Madsen F (2002) Integrating numerical weather predictions in GPS positioning. Proc. of the European navigation conference GNSS 2002, Copenhagen, Published by Nordic Navigation Forum, 1-8

Jupp SM, Powe J, Owen J, Butcher (2003) Use of numerical weather prediction fields for the improvement of tropospheric corrections in global positioning applications. Proc. ION GPS 2003, Institute of Navigation, Portland, Oregon, 9-12 September, 377-389

Marques H A, Monico JFG, Shimabukuro M H, Oyama RT, Aquino M (2012) Satellite clock corrections for real time PPP: a case study in the context of the Brazilian continuous GPS network. Proc. ION GNSS 2012, Nashville, EUA, 17-21

Mesinger F (1984) A blocking technique for representation of mountains in atmospheric models. Riv Meteorol Aeronaut 44:195-202

Mesinger F, Janjic ZI (1974) Noise due to time-dependent boundary conditions in limited area models. The GARP programme on numerical experimentation. Rep. WMO, Geneva 4:31-32

Mesinger F, Lobocki L (1991) Sensitivity to the parameterization of surface fluxes in NMC's Eta model. In 9th conference on numerical weather prediction, Denver. Am Meteorol Soc, pp 213-216

Mesinger F, Janjic ZI, Nickovic S, Gavrilov D, Deaven DG (1988) The step-mountain coordinate: model description, and performance for cases of Alpine lee cyclogenesis and for a case of an Appalachian redevelopment. Mon Weather Rev 116(7):1493-1518

Mesinger F et al (2012) An upgraded version of the Eta model. Meteorol Atmos Phys. doi:10.1007/s00703-012-0182-z

Niell AE (2001) Preliminary evaluation of atmospheric mapping functions based on numerical weather models. Phys Chem Earth $26: 475-480$

Niell AE (1996) Global mapping functions for the atmosphere delay at radio wavelengths. J Geophys Res 101(B2):3227-3246

Richardson LF (1922) Weather prediction by numerical process. Cambridge University Press, London

Rocken C, Sokolovskiy S, Johnson JM, Hunt D (2001) improved mapping of tropospheric delay. J Atmos Oceanic Technol 18:1205-1213

Sapucci LF, Machado LAT, Monico JFG, Plana-Fattori A (2007) Intercomparison of integrated water vapor estimative from multi-sensor in amazonian regions. J Atmos Oceanic Technol 24:1880-1894

Schüler T, Chüler T, Hein G W, Eissfeller B (2003) Improved tropospheric delay modeling using an integrated approach of numerical weather models and GPS. Proc. ION GPS 2003, Portland, Oregon, 600-615

Smith EK, Weintraub S (1953) The constants in the equation for atmospheric refractive index at radio frequencies. J Res Natl Bur Stand 50(1):39-41 (Research Paper 2385) 
Spilker JJ Jr (1996) Tropospheric effects on GPS. Am Inst Aeronaut Astronaut 1:517-546

Teunissen PJG (1998) Quality control and GPS. In: Teunissen PJG, Kleusberg (1998) A GPS for geodesy, Berlin: Springer 2: 271-318

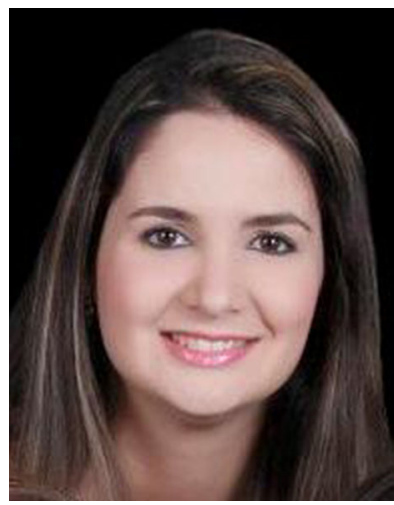

Daniele Barroca Marra Alves is an Assistant Professor at UNESP and Researcher from National Council for Scientific and Technological Development $(\mathrm{CNPq})$. She received her BSc degree in Mathematics in 2001, MSc in 2004, $\mathrm{PhD}$ in 2008, and post-doctorate in 2011, all of them in Cartographic Science, from São Paulo State University. Her research interests are on network-based positioning and atmospheric modeling.

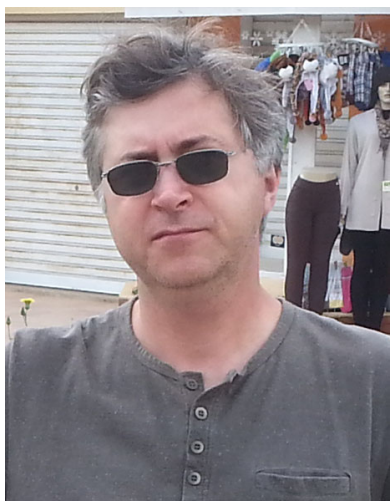

Luiz Fernando Sapucci is a researcher in the Group on Data Assimilation Development of the Center for Weather forecasting and Climate Studies from INPE. He has underground in Math and holds a MSc and $\mathrm{PhD}$ degree in Cartographic Science from São Paulo State University in Presidente Prudente, Brazil. He has worked extensively with the GPS receivers (spatial based and ground based) in meteorological purposes and tropospheric modeling for geodesic positioning over South American using NWP products.

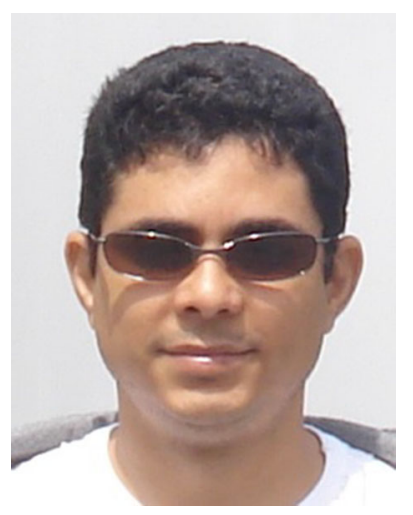

Geodesy and Adjustment, especially those related to GNSS, surveying, and atmospheric sciences.

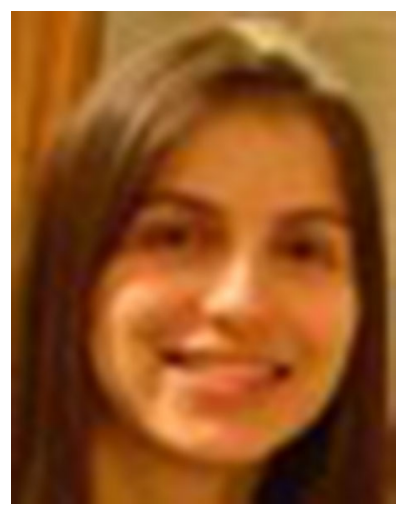

Eniuce Menezes de Souza is a professor at Statistical Department, Maringa State University (UEM), and a researcher from National Council for Scientific and Technological Development $(\mathrm{CNPq})$. She received her $\mathrm{BSc}$ degree in Mathematics in 2001 and her MSc degree (2004) and $\mathrm{PhD}$ in Cartographic Science (2008) from São Paulo State University (UNESP). Her research involves GNSS multipath and scintillation mitigation, multiscale wavelet analysis, and applied statistics, mainly, time series modeling.

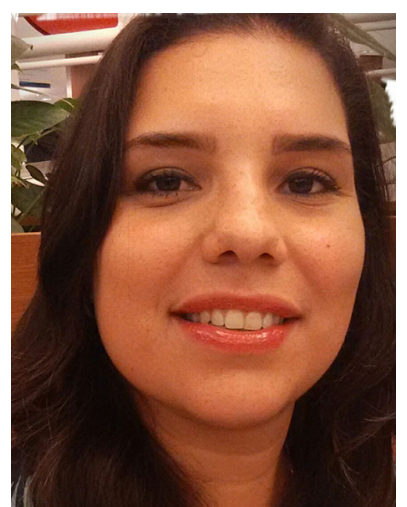

Tayná Aparecida Ferreira Gouveia received her BSc in Mathematics at Sao Paulo State University (FCT-UNESP) Presidente Prudente in 2008, Master in Cartographic Science in 2013, and now she is a PhD student, both in FCT-UNESP. Her research activities involve global geodetic positioning with emphasis on troposphere modeling mainly NWP models.

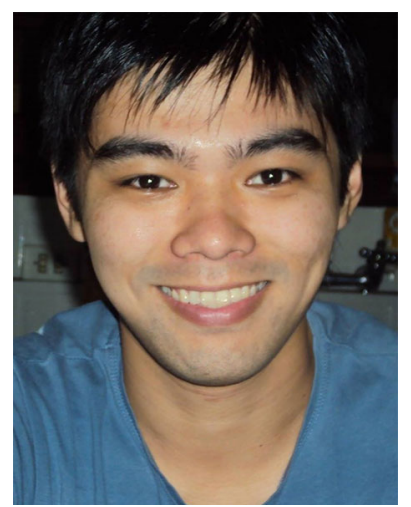

Jackes Akira Magário is a Technical Training Fellow from São Paulo State University in Presidente Prudente, Brazil. He received his $\mathrm{BSc}$ degree in Analysis and Systems Development from Technology College (FATEC) in Presidente Prudente, Brazil. He has worked on a project called "Experiments and analyses of atmospheric models in Network-Based Positioning" using his knowledge to improve network-based system. 